\title{
Candida and Candidiasis - A review article of Virulence Factors
}

\author{
Atyaf Saied Hamied
}

College of Education for Pure Science Ibn-Al-Haitham / University of Baghdad / Baghdad -Iraq

Corresponding author: atyafexeter@gmail.com

Received: 10/ Aug . / 2021 , Accepted: 17/ Oct. / 2021

\begin{abstract}
The occurrences of invasive candidiasis has increased over the previous few decades. Although Candida albicans considers as one of the most common species of organisms, that cause acquired fungal infections.

Candida albicans is an opportunistic fungal pathogen and inherent in as a lifelong, the yeast is present in healthy individuals as a commensal, and can reside harmlessly in human body. However, in immunocompromised individuals, the fungus can invade tissues, producing superficial infections and, in severe cases, life-threatening systemic infections. This review wills emphasis on virulence factor of $C$. albicans including (adhesion, invasion, candida proteinase, and phenotypic switching and biofilm formation.

Invasive Fungal diseases are result in very high morbidity as well as up to $60 \%$ mortality for people with severely susceptible hosts. This review will illustrate briefly the virulence factors in Candida albicans.
\end{abstract}

Keywords: Candida albicans, virulence factors, candidiasis.

\section{Introduction}

Candida albicans is a commensal organism, (normal flora) exist in our gastrointestinal and oral cavity. It is an opportunistic pathogen that colonies different niche in human. Candida can cause life-threating infections especially with immune-suppressed patients. (1) (2)

The pathogenesis of candidiasis can be contributed from expression of various virulence factors like phenotypic switching from yeast to hyphae, adhesion and biofilm formation and secretion of hydrolytic enzymes.

Candida requires several virulence factors to invade the host tissue beginning with adhesion, yeast-hyphae transition and secreted hydrolyses to infect the tissue. (3) Innate immune cells act as mediators to attack microorganisms by C. albicans commensalism

Systemic infections in humans are often caused by microbiome-organisms like bacterial or fungal species that normally residing a different locale in our body, particularly oral cavity or mucosal surfaces. (5) Therefore, a hallmark of $C$. albicans is their aptitude to colonize several niches within the host. (6) Our skin, mouth, oral cavity and gastrointestinal tracts, in addition to our genital are laden with microorganisms. Most of them are commensal microorganisms, which as harmless and provide advantages to humans. (7) phagocytosis. Macrophages and neutrophils are main effector cells that reside in target tissues and organs in order to damage or kill invading fungi via phagocytosis. The antifungal effector cells release antimicrobials such as Reactive Oxygen Species (ROS) or secreting inflammatory signal such as cytokines and chemokines, which are essential to recruit additional immune response cells to the site of infection.

The fungal cell wall is the first point of contact with innate immune cells; thus, it plays an important role in the immune response. The polysaccharide core of the fungal cell wall is highly immunogenic; leading to rapid detection and recognition by innate immune cells especially neutrophils and macrophages. (4)

On the other hand, with the immunocompromised patients, some members of the normal flora, such as $C$. albicans, can cause systematic infections by invading and crossing the host's protective barriers and colonize every niche causing lifethreatening conditions. (8) Oral mucosal infections, characterized by Candida overgrowth linked with an innate immune response, are remarkably common and have an affected on health, which is related the quality of our life. (Fig. 1). 


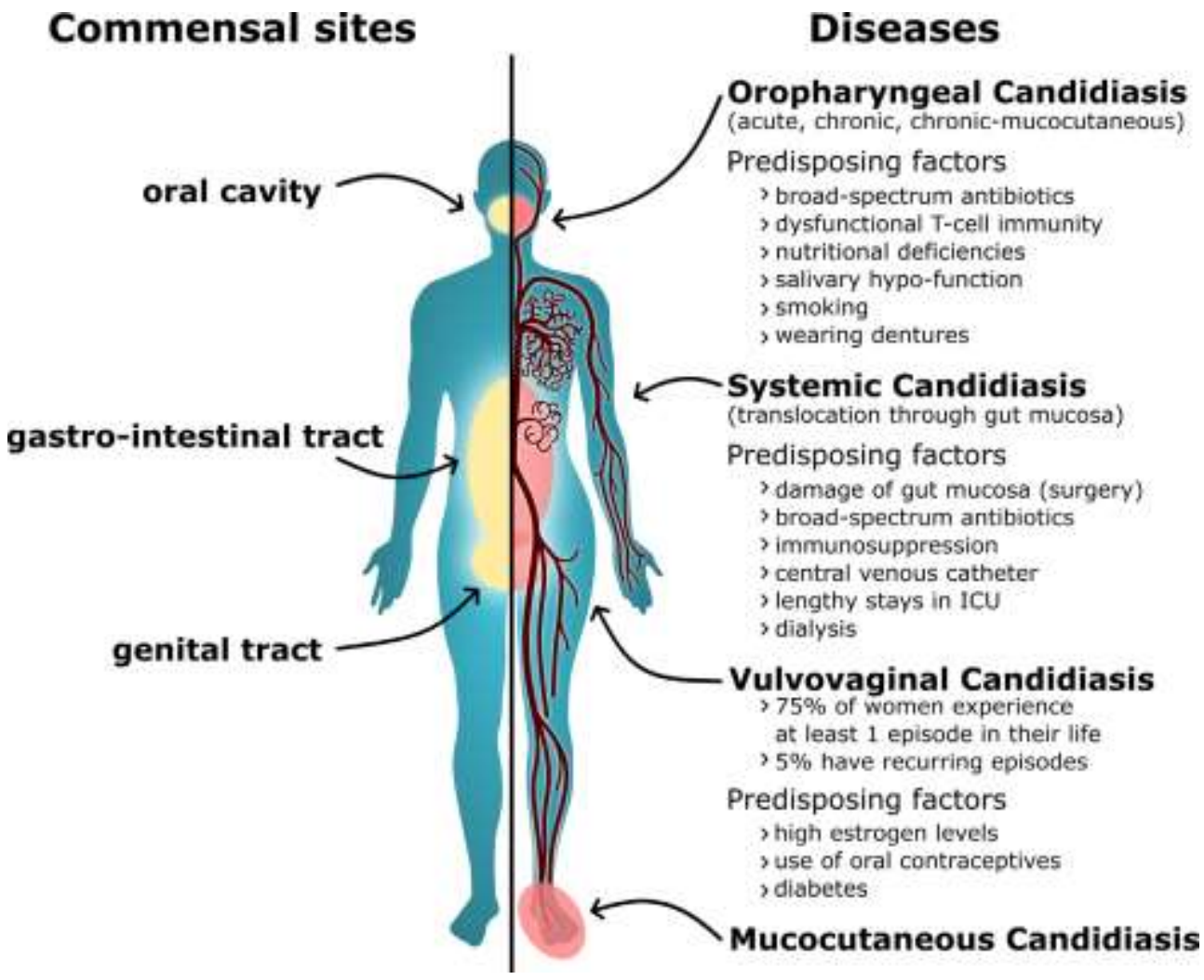

Figure 1. C. albicans commensalism and disease locations on the human body. (8)

Candida has versatility as a pathogen, and adapts as a commensal to various anatomically distinct sites in human body. (9) C. albicans opportunism includes the oral cavity, gastrointestinal tract and the genital tract. C. albicans can infect these sites to cause diseases (candidiasis). It also causes mucocutaneous and superficial infections (i.g. skin and nail). Meanwhile, C. albicans can also cause systemic infections, which often arise via translocation and dissemination of $C$. albicans from the gastrointestinal tract into the bloodstream.

Undoubtly, the understanding about the factors and conditions that enhance $C$. albicans commensalism or opportunism is essential to illustrate the mechanisms that underlie the switching from commensalism to pathogenicity. In fact, the pathogenicity of Candida albicans is mediated by impairing a host's resistance to infection, locally or systemically. (9) Candida species has the ability to cause different types of infection by regulation the expression of its virulence factors and fitness attributes to the different niche of human body. (10)
Pathogenicity and Virulence factors

C. albicans has the ability to cause infections that range from superficial infections of the skin to life-threatening systemic infections. Understanding the pathogenicity of $C$. albicans is essential to develop new therapies and diagnostic antifungal. (11)

\section{Polymorphism}

C. albicans, has four major cellular morphologies, namely yeast cells, pseudohyphae, hyphae, and chlamydospores. These polymorphisms differences between the forms of the growth of $C$. albicans affect the pathogenicity of the fungus. (12) Candida is able to regulate cellular morphogenesis, which is associated with the composition and architecture of the cell wall; this can recognize by the host immune system. Certain conditions can lead fungal cell to grow as yeast or hyphae, and the capability to switch from one form to another in response to external references is rapid. (13) The switching is facilitated by particular conditions; nutrients, a temperature of $37-40^{\circ} \mathrm{C}, \mathrm{pH}, \mathrm{CO} 2$ concentrations of approximately $5.5 \%$, and some 
amino acids. This transition is a requisite for pathogenicity. Yeast forms are more suitable for dissemination in the host tissues, while filamentous forms are required for invading the tissues. Filamentous forms have a powerful ability for adherence and greater invasiveness of the host tissues. (14)

\section{Adhesion and invasion}

C. albicans is a pathogen that is known for its capability to utilize two distinct mechanisms: induced endocytosis and active penetration (15) (16)

(Fig. 2)

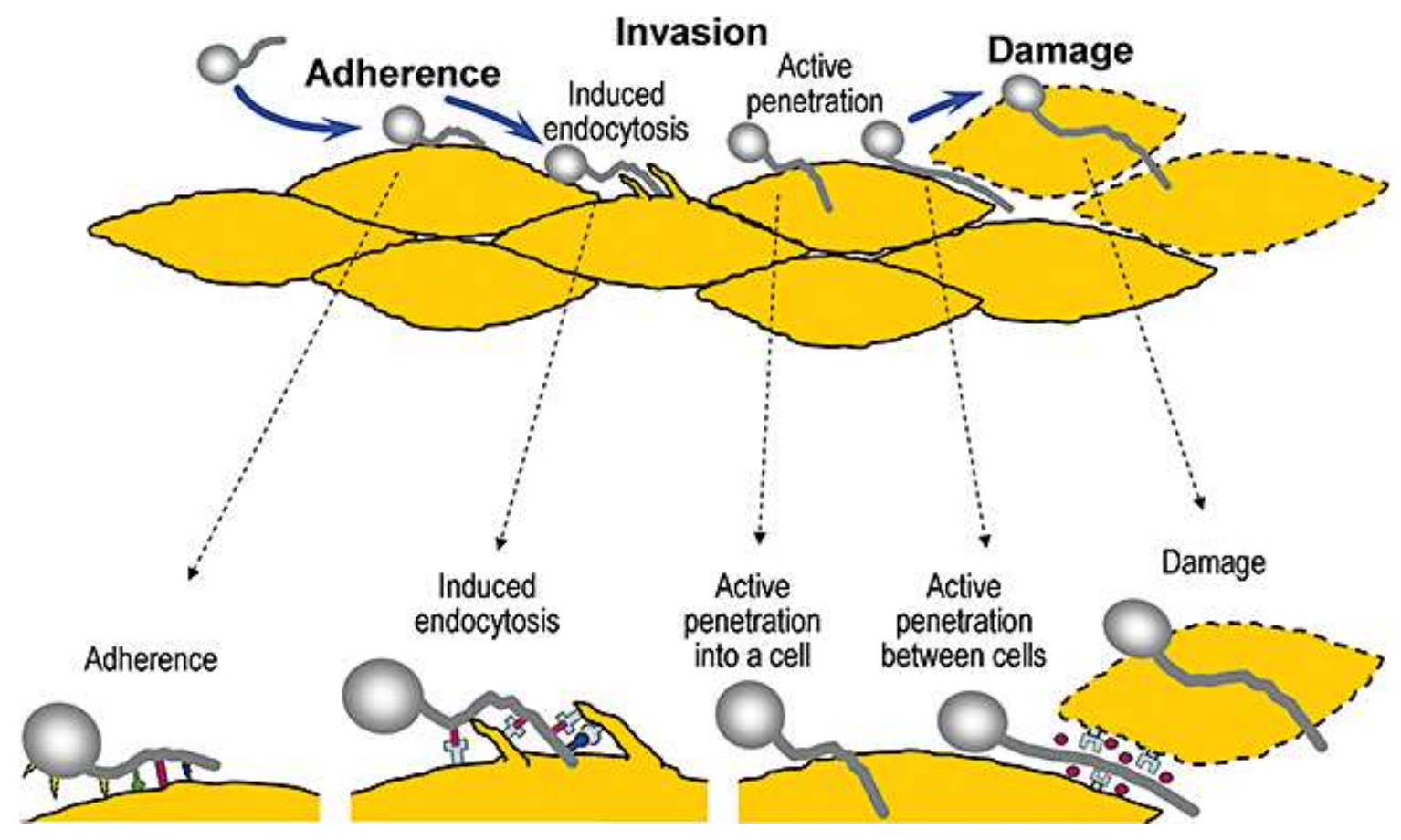

Figure 2. Fungal invasion - An overview of induced endocytosis and active penetration. (33)

Candida cells are notable to adhere to each host cells by specific adhesins such as such als1-7, als9, hwp1, eap1, and pga1, as well as penetrate and degrade the mucosal tissue and vascular barriers. C. albicans can also invade epithelial cells utilizing the mechanism of inducing epithelial cell endocytosis, which is controlled by Mitogen-activated protein (MAP) kinases. It can excite a switch from yeast cells to a hypha form. (17)

In addition, Candida cells promote the production of pseudopods by cells, which engulf Candida cell and pull them inside host tissues. This mechanism requires binding to the epithelial cell surface proteins and is dependent on the active participation of the pathogen - since this route does not take up dead cells. (15)

In fact, invasion via filamentous form of $C$. albicans not only depends on fungal viability and morphology, but also the type of anatomical site of human body. (15) (16) (18)

\section{Secreted hydrolases}

Hydrolytic enzymes are extracellular secreted and the most important enzymes that are responsible for Candida virulence factors and causing pathogenicity (Fig. 3). The enzymes affect $C$. albicans invasion and degradation host proteins such as hemoglobin and keratin as well as alter the structure of the cell membrane in order to facilitate invasion, and host attack by targeting cells of the host's immune system and avoidance of antimicrobial agents. This process occurs not only in $C$. albicans, but also in other Candida species (eg. C. parapsilosis, C. tropicalis and $C$. dubliniensis (19) (20) (21)(22) 
Virulence factors:

\author{
Stage 1: Colonization \\ Epithelial adhesion \\ Nutrient acquisition
}

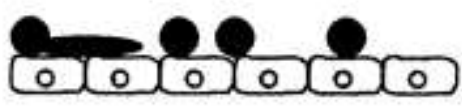

Stage 2: Superficial infection

Epithelial penetration

Degradation of host proteins

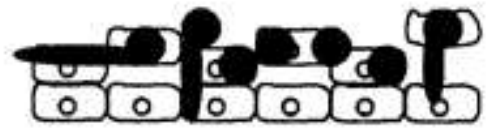

Stage 3: Deep-seated infection

Tissue penetration

Vascular invasion

Immune evasion or escape

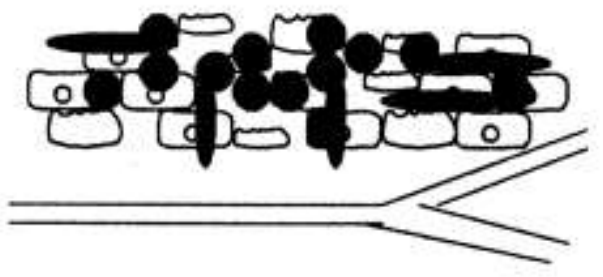

Hydrolytic enzymes

Hypha formation

Host mimicry?

Immunomodulators?

\section{Stage 4: Disseminated infection Endothelial adhesion Infection of other host tissues Activation of coagulation and blood clotting cascades}

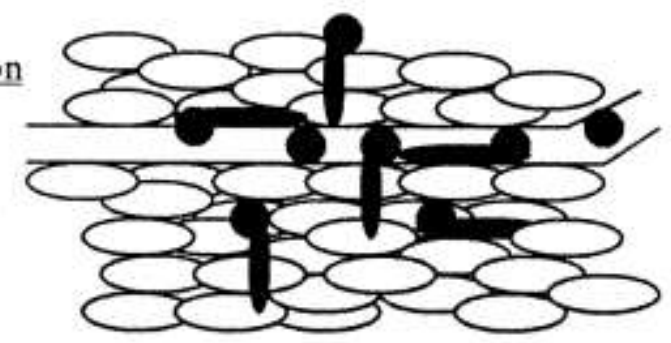

Adhesins Hydrolytic enzymes Hypha formation Phenotypic switching? Antioxidants? Immunomodulators?

Figure 3. Diagram illustrate the contribution of different virulence attributes to $C$. pathogenicity. (32)

\section{pH sensing and metabolic adaptation of Candida}

Many researches have reported that Candida has high ability to adapt sense and grow within different environmental conditions and within distinct niches that exhibit different pHs. This tolerance is important for pathogenicity of $C$. albicans. Generally, pathogenicity of Candida can occur by encountering highly broad of $\mathrm{pHs}$ conditions ( $\mathrm{pH}-2)$ in stomach. In addition, Candida can directly alter $\mathrm{pH}$ condition to mildly neutral and alkaline environment elsewhere because growth of Candida is very poorly at alkaline $\mathrm{pH}$. This highly efficiency of Candida resulting in the inducing transition of Candida cells. (23) (22) The metabolic adaptation of Candida albicans, is an essential factor in a medical field because of its capacity to occupy diverse sites in the human host. In general, human niches contain many different types of assimilable and non-assimilable carbon sources. C. albicans has the ability to grow and assimilate many of these carbon sources but mainly favours glucose. (24) To grow well within different human niches, Candida can exhibit notable metabolic flexibility in human body.

\section{Biofilm formation}

Fungal biofilm formation is a complex process that is highly organized structure, which is distinct by adhesion. Many studies have been carried out extensively in Candida albicans. (25) Biofilms are defined as a ubiquitous in different environments and are formed when microorganisms attach, adhere and accumulate onto surfaces, in which the latter is resistant and can protect from antibiotic treatment. Adhesion of $C$. albicans cells to the surfaces is the first step to stimulate transition, and initiate extracellular matrix, which is organized as a robust structure. 
(26) This is controlled via network of transcription factors of over 1000 genes and that incorporate the expression of adhesins, cellular morphogenesis. (27) (28) Biofilm formation is influenced by different Candida species involved, by distinct patterns of morphogenesis, by environmental agents, and by the type and quality of contact surfaces. In general, cells a biofilm is a cooperating community of adherent that are attached to surfaces and develop by producing extracellular polymers that supply a structural matrix which may assist adhesion. (29) (30) (31) C. albicans biofilms have four distinct developmental phases (31): (i) Spherical yeast cells (early-phase) which promote adherance to the surfaces.

(ii) The intermediate phase, where the basal layer of the matrix with proliferating cells is formed by yeast cells switching to a filamentous form.

(iii) The maturation phase with increased anchoring of fungal cells, growth of hyphae concomitant with the production of extracellular matrix material, arranged to produce a threedimensional architecture.

(iv) The dense network of cells (yeasts, pseudohyphae and hyphae) can slowly disseminate yeast cells from the matrix to seed new sites. (26)

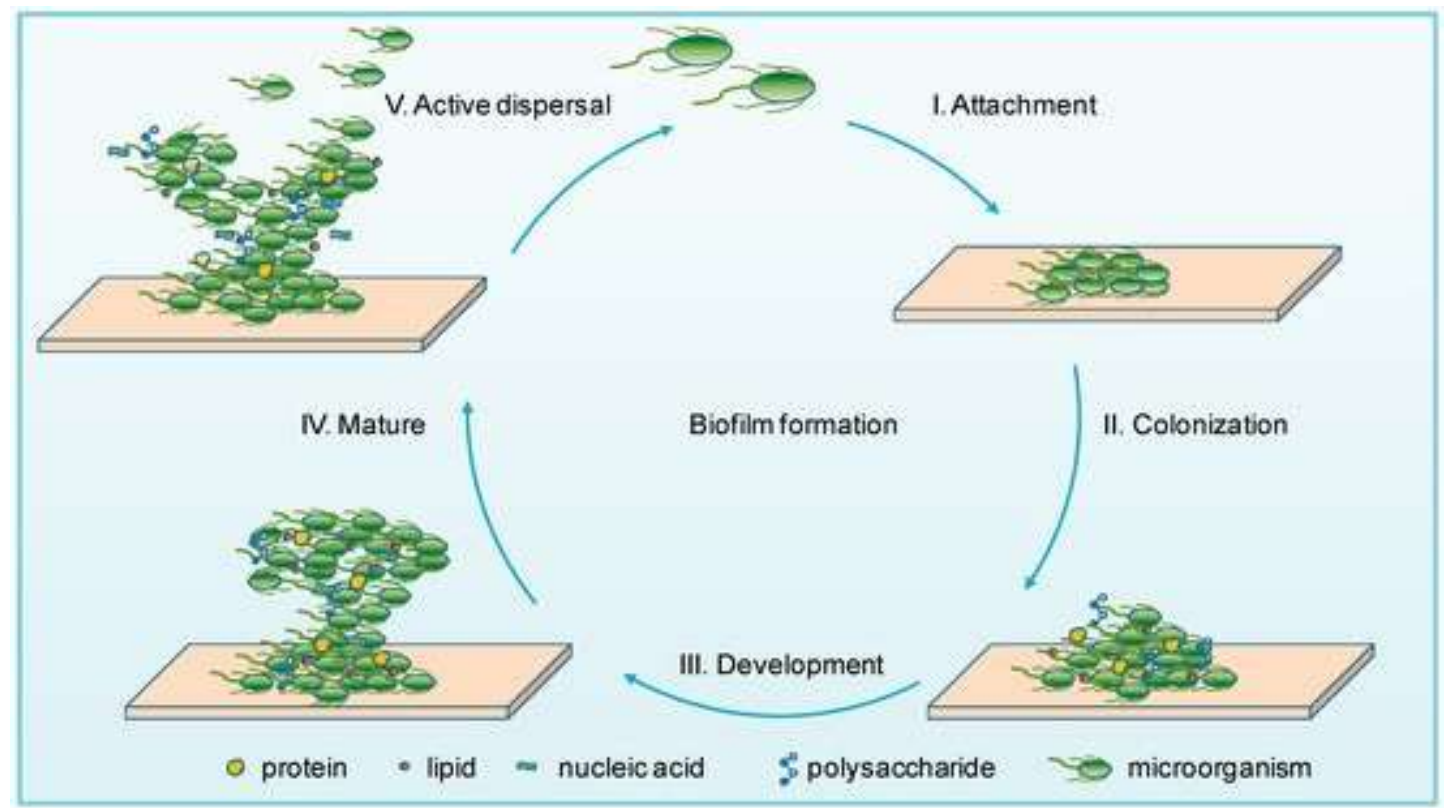

Figure 4. Diagram of microbial biofilm formation. Biofilm formation consists of distinct stages: Attachment, Colonization, Development, Mature and Active dispersal.

\section{Conclusion}

The onset of fungal infection depends on various interactions: between different Candida species, and pathogen-host interactions.

The virulence factors are not a fixed property of a microorganism, because the environment can trigger and regulate the expression of virulence genes.
There are two distinct mechanisms of invasion; fungal-induced endocytosis and active penetration, which resulted in candidiasis. The current review provides comprehensive information on candida and its virulence factor, which may induce strategies for colonization and causing pathogenicity. 


\section{References}

1. Chao $\mathrm{CC} 1$, Hsu PC, Jen $\mathrm{CF}$, Chen $\mathrm{IH}$, Wang $\mathrm{CH}$, Chan HC, Tsai PW, Tung $\mathrm{KC}$, Wang $\mathrm{CH}$, Lan CY, Chuang YJ . Zebrafish as a model host for Candida albicans infection. Infect Immun. (2010); 78: 2512-2521.

2. Torraca V1, Masud S1, Spaink HP1, Meijer AH2. Macrophage-pathogen interactions in infectious diseases: new therapeutic insights from the zebrafish host model. Dis Model Mech. (2014); 7 : 785-797.

3. Koji Y, Haruokaji KN, Makoto M. The role of microfilaments and microtubules during pH-regulated morphological transition in Candida albicans. Microbiol. (1994); 140: 128-287.

4. McKenzie CGJ, Koser U, Lewis LE, Bain JM, Mora-Montes HM, Barker RN, Gow NAR, Erwig LP. Contribution of Candida albicans Cell Wall Components to Recognition by and Escape from Murine Macrophages. Infect Immun. (2010); 78: 1650-1658.

5. Ghannoum MA, Jurevic RJ, Mukherjee $\mathrm{PK}$, et al. Characterization of the oral fungal microbiome (mycobiome) in healthy individuals. PLoS Pathog. (2010) ; 6(1): e1000713. Published 2010 Jan 8 .

6. Pérez JC, Kumamoto CA, Johnson AD. Candida albicans commensalism and pathogenicity are intertwined traits directed by a tightly knit transcriptional regulatory circuit. PLoS Biol. (2013) ;11(3): e1001510.

7. Nash EE, Peters BM, Fidel PL et al. Morphology-Independent Virulence of Candida Species during Polymicrobial Intraabdominal Infections with Staphylococcus aureus. Infect Immun . (2016) ;84: 90-98.
8. d'Enfert C, Kaune AK, Alaban LR, et al. The impact of the Fungus-HostMicrobiota interplay upon Candida albicans infections: current knowledge and new perspectives. FEMS Microbiol Rev. (2021); 45(3): fuaa060.

9. Miceli MH, Díaz JA, Lee SA. Emerging opportunistic yeast infections. Lancet Infect Dis. (2011) Feb; 11(2): 142-151.

10. Pérez JC, Kumamoto CA, Johnson AD. Candida albicans commensalism and pathogenicity are intertwined traits directed by a tightly knit transcriptional regulatory circuit. PLoS Biol. (2013) ;11(3): e1001510.

11. Mayer FL, Wilson D, Hube B. Candida albicans pathogenicity mechanisms. Virulence. (2013) ;4(2): 119-128.

12. Noble SM, Gianetti BA, Witchley JN. Candida albicans cell-type switching and functional plasticity in the mammalian host. Nat Rev Microbiol. (2017); 15(2): 96-108.

13. Whiteway M, Bachewich C. Morphogenesis in Candida albicans. Annual Reviews Microbiology. (2007); 61: $529-553$

14. Jiménez-López C, Lorenz MC. Fungal immune evasion in a model hostpathogen interaction: Candida albicans versus macrophages. PLoS Pathog. (2013);9(11): e1003741.

15. Zhu W, Filler SG. Interactions of Candida albicans with epithelial cells. Cellular Microbiology. (2010); 12(3): 273-282.

16. Naglik JR. Candida Immunity. New Journal of Science. (2014); 27p. Review article. 
17. Csank C, Makris C, Meloche S, Schroppel K, Rollinghoff M, Dignard D, Thomas DY, Whiteway M. Derepressed hyphal growth and reduced virulence in a VH1 family-related protein phosphatase mutant of the human pathogen Candida albicans. Molecular Biology Cell. (1997); 8(12): 2539-2551.

18. Dalle F, Wachtler B , L'Ollivier C, Holland G, Bannert N, Wilson D, Labruère $\mathrm{C}$, Bonnin $\mathrm{A}$, Hube $\mathrm{B}$. Cellular interactions of Candida albicans with human oral epithelial cells and enterocytes. Cellular Microbiology. (2010); 12(2): 248-271.

19. Naglik JR, Challacombe SJ, Hube B. Candida albicans secreted aspartyl proteinases in virulence and pathogenesis. Microbiology and Molecular Biology Reviews. (2003); 67(3): 400- 428.

20. De Viragh PA, Sanglard D, Togni G, Falchetto R, Monod M. Cloning and sequencing of two Candida parapsilosis genes encoding acid proteases. General Microbiology. (1993); 139: 335-342.

21. Bader O, Naglik J, Albrecht A, Bader $\mathrm{O}$, Hube B. Candida albicans proteinases and host / pathogen interactions. Cell microbiology. (2004) ; 6(10): 915-926.

22. Mayer FL, Wilson D, Hube B. Candida albicans pathogenicity mechanisms. Virulence. (2013); 4(2): 119-128.

23. Vylkova S, Carman,A J, Danhof H A, Collette JR, Zhou H, Lorenz MC. The fungal pathogen Candida albicans autoinduces hyphal morphogenesis by raising extracellular pH. mBio. (2011); 2 (3): $1-12$.

24. Ene IV, Lohse MB, Vladu AV, Morschhäuser J, Johnson AD, Bennett RJ. Phenotypic Profiling Reveals that
Candida albicans Opaque Cells Represent a Metabolically Specialized Cell State Compared to Default White Cells. mBio. (2016); 7(6): e01269-16. Published 2016 Nov 22.

25. Donlan RM, Costerton JW. Biofilms: survivalmechanisms of clinically relevant microorganisms. Clin.Microbiol. Rev. (2002); 15(2): 167-19.

26. Nobile CJ, Johnson AD. Candida albicans biofilms and human disease. Annual Review of Microbiology. (2015); 69: 71-92.

27. Finkel JS, Mitchell AP. Genetic control of Candida albicans biofilm development. Nat Rev Microbiol. (2011); 9(2): 109-118.

28. Lohse MB, Gulati M, Johnson AD, Nobile CJ. Development and regulation of single- and multi-species Candida albicans biofilms. Nat Rev Microbiol. (2018); 16(1):19-31.

29. onlan RM, Costerton JW. Biofilms: survivalmechanisms of clinically relevant microorganisms. Clin.Microbiol. Rev. (2002); 15(2): 167-19.

30. Kokare CR, Chakraborty S, Khopade NA, Mahadik KR. Biofilm, Importance, and application. Indian journal of biotechnology. (2009); 8: 159-168.

31. Kojic EM, Darouiche RO. Candida Infections of Medical Devices. Clinical Microbiology Reviews. (2004); 17(2): 255-267.

32. Naglik JR, Challacombe SJ, Hube B. Candida albicans secreted aspartyl proteinases in virulence and pathogenesis. Microbiol Mol Biol Rev. (2003); 67(3): 400-428.

33. Yin W, Wang Y, Liu L, He J. Biofilms: The Microbial "Protective Clothing" in Extreme Environments. Int. J. Mol. Sci. (2019); 20, 3423. 
Vol.15 No.2

\section{Journal of Biotechnology Research Center}

Published Online: (December) 2021 https://doi.org/10.24126/jobrc.2021.15.2.606 E-ISSN: 2708-1370

الكانديدا و داء المبيضات - إستعراض عوامل الضراوة

أطياف سعيد حميذ

كلية التربية ابن الهيثم للعلوم الصرفة / جامعة بغداد / العراق - بغداد

Corresponding author: atyafexeter@gmail.com

الخلاصة

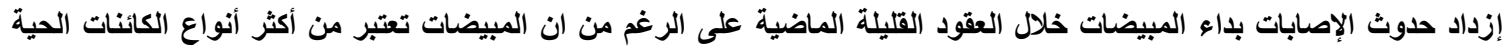

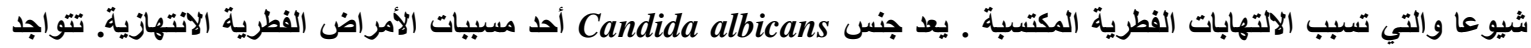

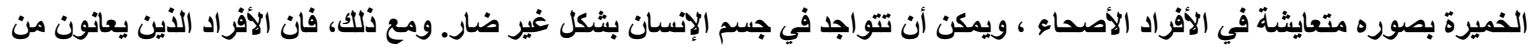

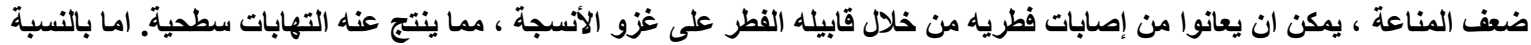

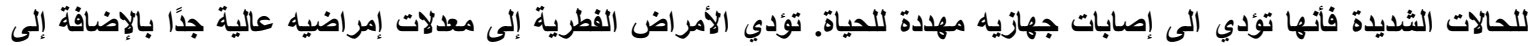

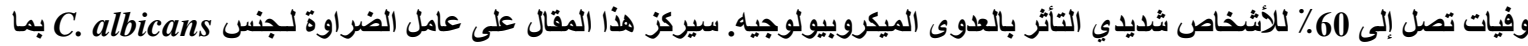

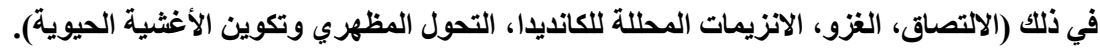

